University of Wollongong

Research Online

Faculty of Engineering and Information

Faculty of Engineering and Information

Sciences - Papers: Part A

Sciences

$1-1-2016$

\title{
A wideband F-shaped patch antenna for S-band CubeSats communications
}

Faisel Em M Tubbal

University of Wollongong, femt848@uowmail.edu.au

Raad Raad

University of Wollongong, raad@uow.edu.au

Kwan-Wu Chin

University of Wollongong, kwanwu@uow.edu.au

Follow this and additional works at: https://ro.uow.edu.au/eispapers

Part of the Engineering Commons, and the Science and Technology Studies Commons

Research Online is the open access institutional repository for the University of Wollongong. For further information contact the UOW Library: research-pubs@uow.edu.au 


\title{
A wideband F-shaped patch antenna for S-band CubeSats communications
}

\author{
Abstract \\ A wideband S-band F-shaped patch antenna is proposed for CubeSats communications. To broaden \\ bandwidth, it uses two arms with different lengths to generate a second resonant frequency. The effect of \\ the arm length and width on the return loss, resonant frequency and impedance bandwidth on a $3 \mathrm{U}$ \\ CubeSat is studied. The simulation results show that the antenna achieves a wideband of $1121 \mathrm{MHz}$ \\ $(1.606-2.727 \mathrm{GHz})$ with a return loss below $-10 \mathrm{~dB}$ over the entire frequency band from 1.606 to 2.727 \\ $\mathrm{GHz}$. The antenna has a high gain of $8.51 \mathrm{~dB}$ and a small return loss of $-32.85 \mathrm{~dB}$ at $2.45 \mathrm{GHz}$.

\section{Keywords} \\ wideband, communications, cubesats, f-shaped, patch, antenna, s-band \\ Disciplines \\ Engineering | Science and Technology Studies

\section{Publication Details} \\ F. Em. Tubbal, R. Raad \& K. Chin, "A wideband F-shaped patch antenna for S-band CubeSats \\ communications," in 10th International Conference on Signal Processing and Communication Systems \\ (ICSPCS), 2016, pp. 1-4.
}




\title{
A Wideband F-shaped Patch Antenna for S-band CubeSats Communications
}

\author{
Faisel Em Tubbal ${ }^{1,2}$, Member, IEEE, Raad Raad ${ }^{1}$, Member, IEEE, Kwan-Wu Chin ${ }^{1}$ \\ ${ }^{1}$ School of Electrical, Computer and Telecommunications Engineering, University of Wollongong, NSW, Australia, 2522 \\ ${ }^{2}$ Technological Projects Department, the Libyan Center for Remote Sensing and Space Science, Tripoli, Libya \\ femt848@uowmail.edu.au, raad@uow.edu.au, kwanwu@uow.edu.au
}

\begin{abstract}
A wideband S-band F-shaped patch antenna is proposed for CubeSats communications. To broaden bandwidth, it uses two arms with different lengths to generate a second resonant frequency. The effect of the arm length and width on the return loss, resonant frequency and impedance bandwidth on a $3 \mathrm{U}$ CubeSat is studied. The simulation results show that the antenna achieves a wideband of $1121 \mathrm{MHz}(1.606-$ $2.727 \mathrm{GHz}$ ) with a return loss below $-10 \mathrm{~dB}$ over the entire frequency band from 1.606 to $2.727 \mathrm{GHz}$. The antenna has a high gain of $8.51 \mathrm{~dB}$ and a small return loss of $-32.85 \mathrm{~dB}$ at 2.45 GHz.
\end{abstract}

Index Terms - CubeSats; circularly polarized; axial ratio; gain

\section{INTRODUCTION}

CubSats are revolutionizing the space industry and are critical for space research [1]. They have a mass ranging from 1.3 to $6 \mathrm{~kg}$ and a fixed face size of $10 \mathrm{~cm} \times 10 \mathrm{~cm}$ with three different lengths: $10 \mathrm{~cm}, 20 \mathrm{~cm}$, and $30 \mathrm{~cm} \mathrm{[2,3].} \mathrm{Fig.} 1$ shows an example $3 \mathrm{U}(10 \mathrm{~cm} \times 10 \mathrm{~cm} \times 30 \mathrm{~cm})$ CubeSat that is currently under development at the University of Wollongong (UoW). Compared to conventional satellites, CubeSats have a short development period of about one year and provide low cost access to space [2]. One advantage of CubeSats is that several dozens of CubeSats can be placed in a single launcher tube. To date, CubeSats are used for remote sensing applications [1, 4], including monitoring deforestation and agriculture yield, mapping and geospatial services, emergency responses, tracking of ships, and they are also used to aid oil exploration by processing and analysing satellite images of the Earth's surface [5].

CubeSats require a wideband high gain antenna for communications between satellites and a ground station. This antenna provides a link with a ground station for uplink telecommands as well as a downlink to send telemetry and data (images). The main design challenges are the limited size and low mass of CubeSats. This means any designed antenna must satisfy the size constraints of CubeSats.

To address the aforementioned challenges, patch antennas are ideal because they have a low profile, lightweight, are mechanically robust and are easily integrated with electronic devices [2]. In addition, they are available commercially for a variety of frequency spectrums including the popular high bitrate 2.4-2.5 GHz unlicensed Industrial, Scientific and Medical (ISM) band. However, they have narrow bandwidth and low gains at high frequencies; i.e., $2.40-2.50 \mathrm{GHz}$ [6]; both of which decrease data bitrate.

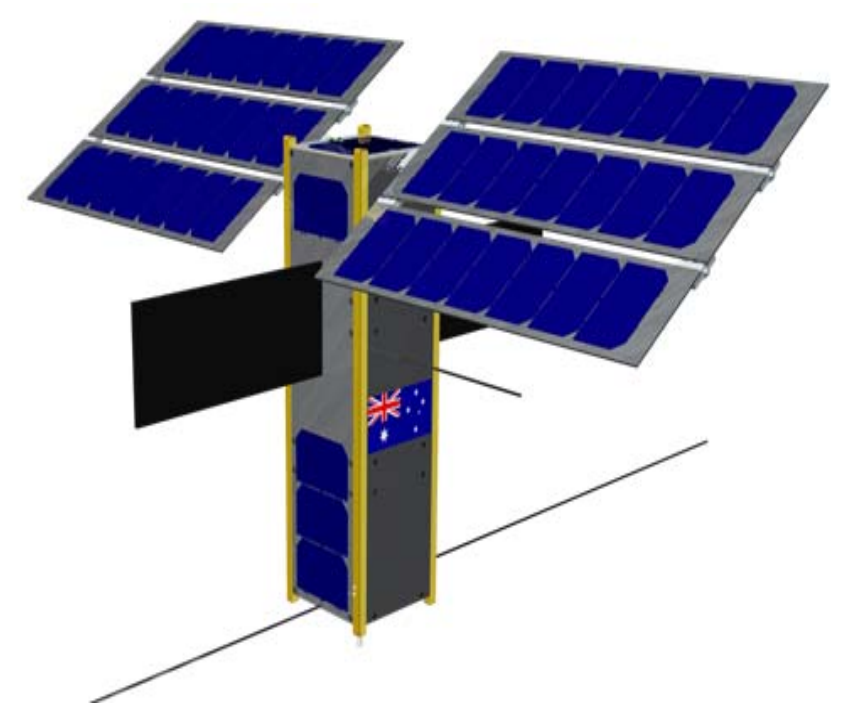

Fig. 1. UoW's $3 U$ cube satellite $(10 \mathrm{~cm} \times 10 \mathrm{~cm} \times 30 \mathrm{~cm})$.

There are many approaches to widen the bandwidth of patch antennas. One common technique is to use U-slot and L-slit patch antenna geometries. The main idea is to incorporate a folded inner small patch within a larger patch. The authors of [7] reported a bandwidth enhancement of $53.54 \%(3.57-6.18 \mathrm{GHz})$ at the resonant frequency of $4.5 \mathrm{GHz}$ 
and $45.12 \%$ (4.26-6.75 GHz) at 5.5 GHz. However, their main limitation is the resulting low gains of about $2.5 \mathrm{~dB}$. Another approach is by interleaving two patch antennas [8]. The main idea is to use a folded ramp-shaped feed and one pin in the centre of the upper patch to increase bandwidth. The authors also used shorting pins between the patches and the ground plane to miniaturize the antenna's size. Although the modified S-band shorted patch antenna presented in [8] has a wideband of $320 \mathrm{MHz}(2.200-2.520 \mathrm{GHz})$, its size is reasonably large at $83 \times 83 \mathrm{~mm}^{2}$, making it unsuitable for used on CubeSats.

In this paper, we propose a wideband $2.45 \mathrm{GHz}$ F-shaped patch antenna for CubeSats communications. The main idea is to feed the resonance arms of the upper F-shaped patch by a folded ramp-shaped patch. This generates two resonant frequencies and hence achieves a wide bandwidth. Moreover, three shorting pins between the edges of the upper patch (F-shaped patch) and the ground plane are used to increase the effective electrical length of the patch and hence reduces its physical size. In addition, shorting pins are also used to lower the resonant frequency and widen bandwidth. Compared to all previous S-band planar antennas, see our survey in [2] and listed in Table 1 for convenience, our design achieves a higher gain, i.e., $8.51 \mathrm{~dB}$, has a wider bandwidth of $1121 \mathrm{MHz}(1.606-2.727 \mathrm{GHz})$ and has small size of $33.8 \times 88.4 \mathrm{~mm}^{2}$, which means less surface area on a CubeSat; i.e., $29.8 \%$ for $1 \mathrm{U}$ and $14.9 \%$ for $2 \mathrm{U}$.

Table 1. Comparison between S-band patch antennas for CubeSats

\begin{tabular}{|c|c|c|c|c|}
\hline Ref. & $\begin{array}{c}\text { Antenna } \\
\text { Type } \\
\end{array}$ & $\begin{array}{l}\text { Gain } \\
\text { [dB] }\end{array}$ & $\begin{array}{c}\text { Bandwidth } \\
\text { [MHz] }\end{array}$ & $\begin{array}{c}\text { Size } \\
{\left[\mathrm{mm}^{2}\right]}\end{array}$ \\
\hline [9] & $\begin{array}{l}\text { Four-element } \\
\text { microstrip } \\
\text { patch array }\end{array}$ & 7.1 & 320 & $15 \times 15$ \\
\hline [8] & $\begin{array}{l}\text { Shorted patch } \\
\text { antenna }\end{array}$ & 3.51 & 320 & $83 \times 83$ \\
\hline [10] & Patch antenna & $\mathrm{n} / \mathrm{a}$ & 80 & $80 \times 80$ \\
\hline [11] & $\begin{array}{l}\text { Circular patch } \\
\text { antennas }\end{array}$ & 5.96 & 50 & $3.14 \times 1.2^{2}$ \\
\hline [12] & $\begin{array}{l}\text { Wire patch } \\
\text { antenna }\end{array}$ & $\mathrm{n} / \mathrm{a}$ & 116.34 & $3.14 \times 2.7^{2}$ \\
\hline $\begin{array}{l}\text { Proposed } \\
\text { antenna }\end{array}$ & $\begin{array}{l}\text { F-shaped } \\
\text { patch }\end{array}$ & 8.51 & 1121 & $33.8 \times 88.4$ \\
\hline
\end{tabular}

\section{ANTENNA DESIGN AND STRUCTURE}

Fig. 2 shows the structure of the proposed antenna. It consists of an upper F-shaped patch, a folded patch feed and three shorting pins. The antenna uses the CubeSat's surface as a ground plane with air substrate. It is fed by a $50 \Omega$ coaxial probe at $\left(\mathrm{x}_{0}, \mathrm{y}_{0}\right)$ and supported by the three shorting pins that are connected between the upper F-shaped patch and ground plane. These shorting pins generate low resonant frequencies and hence increases bandwidth and help reduce the size of the antenna. The diameter of the shorting pins that provides the optimal antenna bandwidth is $3.64 \mathrm{~mm}$ Moreover, to reduce the coaxial probe length and inductance at the feed section, the folded patch technique [13] is used and fed at a height of $h_{1}=18.4 \mathrm{~mm}$. The length of the arm $L_{1}$ and the width of the slot $\mathrm{W}_{2}$ are studied using the High Frequency Simulator Structure (HFSS) [14] to obtain their optimal value. These parameters play a significant role in enhancing the antenna's performance; i.e., bandwidth, resonant frequency and return loss. They also produce two resonant frequencies and hence improve bandwidth. The optimal parameter values of the proposed antenna are as follows: $\mathrm{h}_{1}=18.4 \mathrm{~mm}, \mathrm{~h}_{2}=9.5 \mathrm{~mm}, \mathrm{~L}=33.8 \mathrm{~mm}, \mathrm{~W}=88.4$ $\mathrm{mm}, \mathrm{W}_{1}=20.8, \mathrm{~W}_{2}=15.6, \mathrm{~W}_{3}=36.4 \mathrm{~mm}, \mathrm{~L}_{1}=20.8 \mathrm{~mm}, \mathrm{~L}_{2}=$ $23.4 \mathrm{~mm}, \mathrm{~L}_{3}=10.4 \mathrm{~mm}, \mathrm{~L}_{4}=13 \mathrm{~mm}, \mathrm{x}_{0}=0 \mathrm{~mm}$ and $\mathrm{y}_{0}=10.4$ $\mathrm{mm}$.

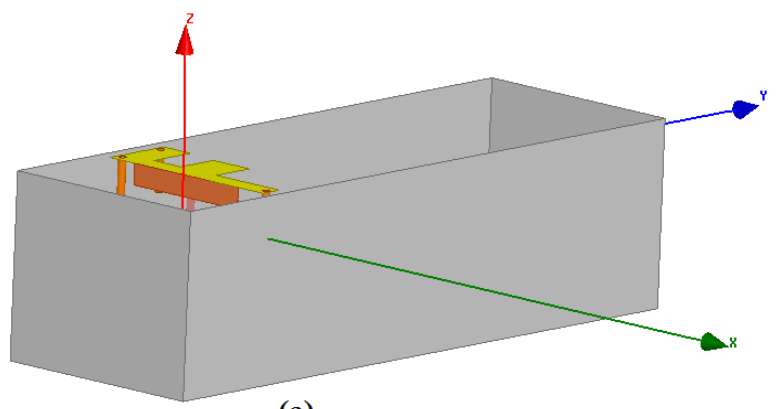

(a)

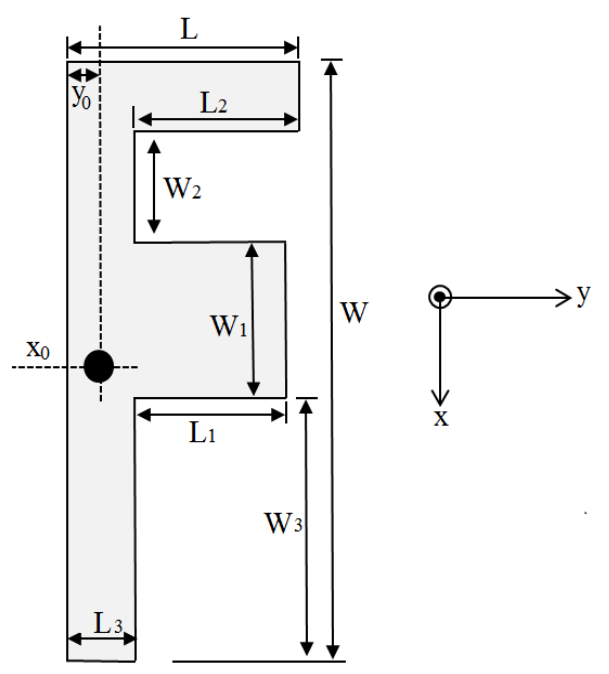

(b)

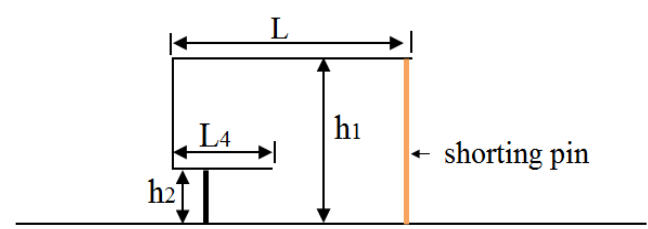

(c)

Fig. 2. Configuration of the wideband F-shaped patch antenna. (a) a 3D view of the proposed antenna as modeled in HFSS on a 3U cubeSat, (b) top view, and (c) side view.

\section{RESULTS AND DISCUSSION}

The simulation results are obtained using HFSS. Fig. 3 shows the simulated return losses of our F-shaped patch antenna with the following $\mathrm{L}_{1}$ lengths: $18.8,20.8$ and 22.8 $\mathrm{mm}$. Other parameters are fixed. We can see that the second (fundamental) resonant frequency increases when the length of $\mathrm{L}_{1}$ increases while the first resonant frequency is barely 
affected. The required resonant frequency of $2.45 \mathrm{GHz}$ is obtained at $\mathrm{L}_{1}=20.8$. Moreover, when $\mathrm{L}_{1}$ is set to $18.8 \mathrm{~mm}$, the F-shaped patch antenna becomes a dual-band antenna rather than wideband. The most suitable length is $L_{1}=20.8$ $\mathrm{mm}$ as it provides wide bandwidth; i.e., $1121 \mathrm{MHz}$, and small return loss of $-32.85 \mathrm{~dB}$ at resonant frequency $2.45 \mathrm{GHz}$. This means good impedance matching.

Fig. 4 shows the simulated return loss of the proposed antenna with different slot width values and $L_{1}=20.8 \mathrm{~mm}$. The width $\mathrm{W}_{2}$ is varied from 8.6 to $22.6 \mathrm{~mm}$. We see that the slot width $\mathrm{W}_{2}$ has no effect on the resonant frequency and the bandwidth of the F-shaped patch antenna. However, the return loss $\mathrm{S}_{11}$ increases when the width $\mathrm{W}_{2}$ decreases. In addition, when $\mathrm{W}_{2}$ is set to $22.6 \mathrm{~mm}$, a dual band resonant mode is obtained. Hence, small $-10 \mathrm{~dB}$ impedance bandwidth, i.e., $600 \mathrm{MHz}(2.12-2.72 \mathrm{GHz})$ is achieved. The most suitable width is $\mathrm{W}_{2}=15.6 \mathrm{~mm}$ as it provides an impedance bandwidth of $1121 \mathrm{MHz}(1.606-2.727 \mathrm{GHz})$ and a small return loss of $-32.85 \mathrm{~dB}$ at resonant frequency 2.45 GHz. This means large bandwidth, high bitrate, low reflected power and good impedance matching; see Fig. 4 and 7.

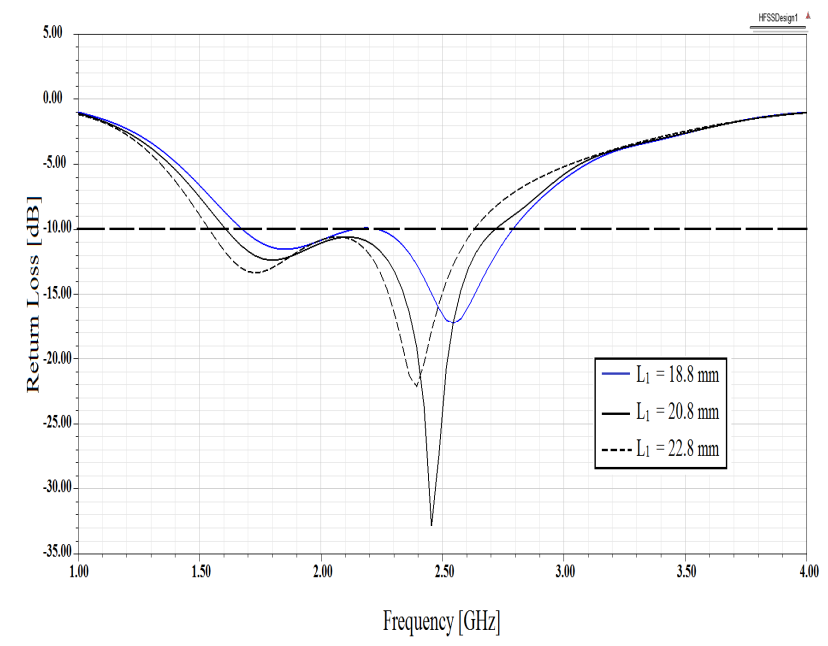

Fig 3. Simulated return loss against frequency for various $L_{1}$

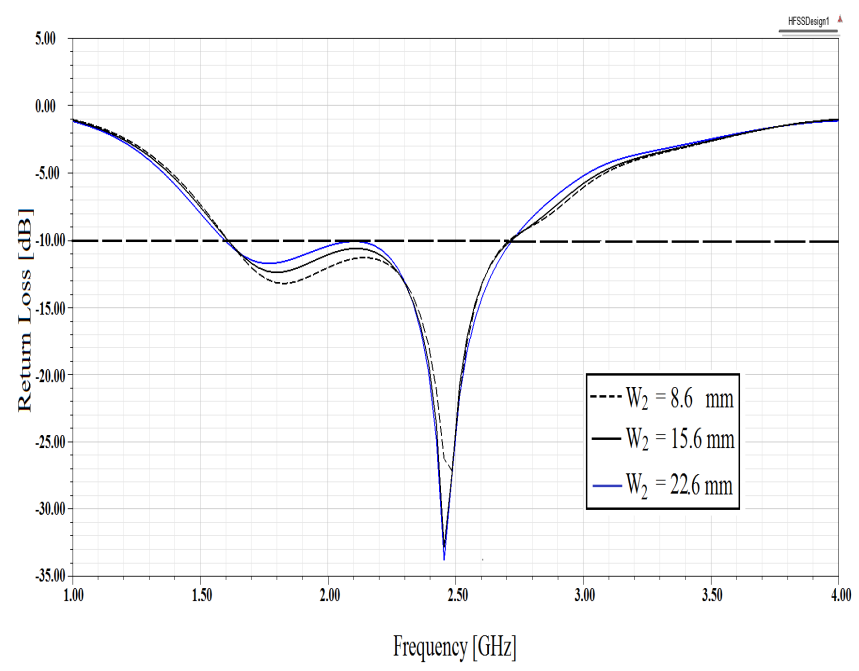

Fig. 4. Simulated return loss against frequency for various W2
Fig. 5 and 6 show the 3D and 2D simulated radiation pattern at the resonant frequency of $2.45 \mathrm{GHz}$. The back lobe is significantly reduced because we use a large ground plane (CubeSat's surface) and hence a unidirectional pattern is achieved. This is important as it increases the total gain and decreases the interference with the electronics inside the CubeSat. The maximum achieved gain is about $8.51 \mathrm{~dB}$ with a $20^{\circ}$ elevation tilt and Half Power Beamwidth (HPBW) of $98.34^{0}$ at a resonant frequency of $2.45 \mathrm{GHz}$.
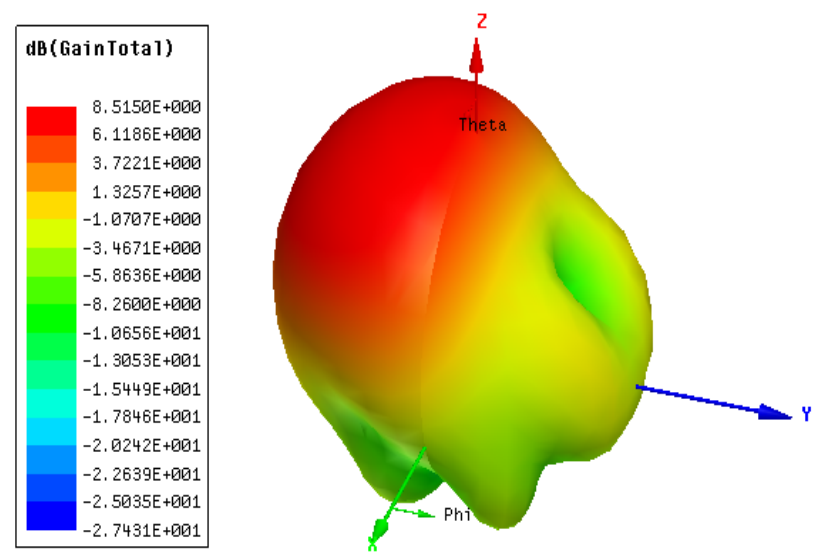

Fig. 5. 3D gain at $2.45 \mathrm{GHz}$.

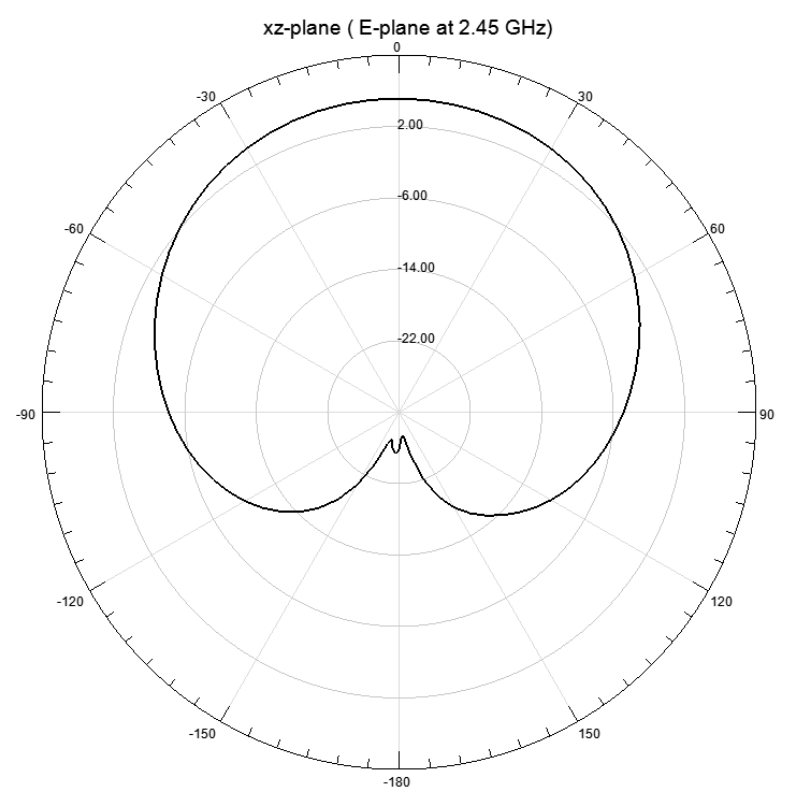

Fig. 6. Simulated radiation pattern of F-shaped patch antenna at $2.45 \mathrm{GHz}$

Fig. 7 depicts the simulated input impedance (real and imaginary parts) of the F-shaped patch antenna in the $1-3.5$ $\mathrm{GHz}$ frequency bands. We note that good impedance matching is obtained at $2.45 \mathrm{GHz}$ with almost $50 \Omega$ real part and zero imaginary parts (inductance). The input impedance (real and imaginary parts) is $50+\mathrm{j} 0 \Omega$ at the resonant frequency of $2.45 \mathrm{GHz}$. This means very small reflection with most power radiated into space. 


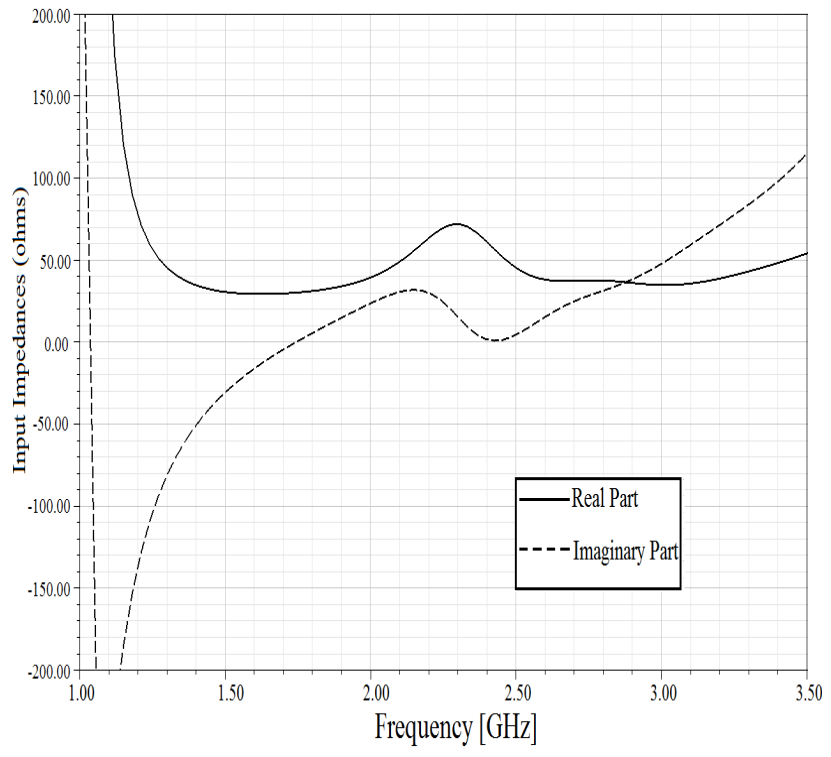

Fig. 7. Input impedance of the proposed antenna

\section{CONCLUSION}

We have proposed a wideband F-shaped patch antenna for S-band CubeSats communications. The simulated return loss is below $-10 \mathrm{~dB}$ from 1.606-2.727 $\mathrm{GHz}$ (bandwidth= 1121 $\mathrm{MHz}$ ). The antenna size is small; i.e., $33.8 \times 88.4 \mathrm{~mm}^{2}$. Simulated results show it has a resonant frequency of 2.45 $\mathrm{GHz}$, a small return loss of $-32.85 \mathrm{~dB}$, a high gain of $8.51 \mathrm{~dB}$ and good impedance matching of $50 \Omega$.

\section{REFERENCES}

[1] R. A. Deepak and R. J. Twiggs, "Thinking out of the box: space science beyond the cubesat," Journal of Small Satellites, vol. 1, pp. 3-7, 2012.

[2] F. EM. Tubbal, R. Raad, and K-W. Chin, "A survey and study of planar antennas for pico-satellites," IEEE Access, vol. 3, pp. 2590-2612, December 2015.

[3] F. Em. Tubbal, R. Raad, K-W. Chin, and B. Butters, "A high gain s-band CPW-fed slot antenna for cubesat Communications " unpublished., pp. 1-15, 2016.

[4] J. Bouwmeester and J. Guo, "Survey of worldwide pico-and nanosatellite missions, distributions and subsystem technology," Acta Astronautica, vol. 67, pp. 854-862, October-November 2010.

[5] L. Qiao, E. Glennon, A. G. Dempster, and S. Chaoui, "Using cubesats as platforms for remote sensing with satellite navigation signals," IEEE International Conference on Geoscience and Remote Sensing Symposium, Melbourne, Australia, July 2013, pp. 852-855.

[6] J. Liang and H. Y. D. Yang, "Radiation characteristics of a microstrip patch over an electromagnetic bandgap surface," IEEE Transactions on Antennas and Propagation, vol. 55, pp. 1691-1697, June 2007.

[7] C. Y. Chiu, K. M. Shum, C. H. Chan, and K. M. Luk, "Bandwidth enhancement technique for quarter- wave patch antennas," IEEE Antennas and Wireless Propagation Letters, vol. 2, pp. 130-132, 2003.

[8] F. Em . Tubbal, R. Raad, K.-W. Chin, and B. Butters, "S-band shorted patch antenna for inter pico satellite communications," IEEE 8th International Conference on Telecommunication System, Services and Application, Kuta, Bali, Indonesia, October 2014, pp. 1-4.

[9] S-L. Ma, C.J. Shih, and J-S. Row, "Four-element microstrip array with polarization diversity," Microwave and Optical Technology Letters, vol. 55, pp. 1653-1657, July 2013.

[10] R. Montaño, N. Neveu, S. Palacio, E. Martinez, D. R. Jackson, J. Chen, P. W. Fink, and R. S. Provence, "Development of low-profile antennas for cubesats," Conference on Small Satellite, Logan, UT, United State, August 2014.

[11] R. O. Ouedraogo, E. J. Rothwell, A. R. Diaz, K. Fuchi, and A. Temme, "Miniaturization of patch antennas using a metamaterial- inspired technique," IEEE Transactions on Antennas and Propagation, vol. 60, no. 5, pp. 2175-2182, May 2012.

[12] R. Addaci, A. Diallo, P. L. thuc, and R. Staraj, "Efficient miniaturization technique for wire patch antennas," Microwave and Optical Technology Letters, vol. 54, no. 5, pp. 1325-1327, May 2012.

[13] C. Y. Chiu, H. Wong, and C. H. Chan, "Study of small wideband folded-patch-feed antennas," IET Microwaves, Antennas and Propagation, vol. 1, pp. 501-505, April 2007.

[14] High Frequency Structure Simulator [online] available: http://www.ansys.com/.
(HFSS) 